\section{Los errores cometidos}

Durante el Encuentro sobre Comunicación Alternativa y Popular; José Martínez Terrero, S.J. repasó las principales corrientes de la Comunicación Alternativa y Popular, desde los años 60 hasta el presente, rescatando sus aportes conceptuales y

prácticos, asi como los errores cometidos. $A$ continuación publicamos un extracto que destaca la reflexión crítica y autocrítica. Los lectores pueden obtener el documento completa solicitándolo al: Centre for the Study of Communication and Culture 221 Goldburst Terrace London NW6 3EP, Inglaterra

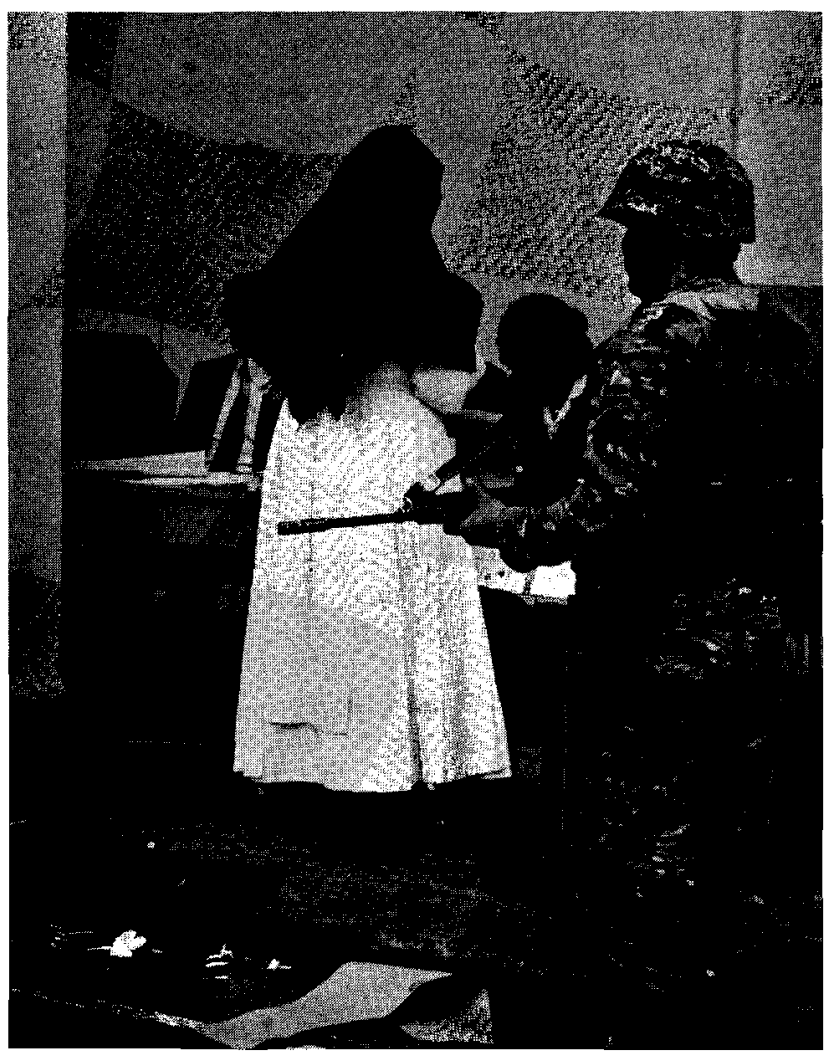

Elecciones
A

mérica Latina es famosa por sus logros en el campo de la comunicación alternativa y popular (CAP). Pero los errores cometidos, en las casi cuatro décadas de experiencias, no se expresan aún con suficiente claridad. Se destaca:

* La tendencia a ignorar la teoría mediática y los aspectos afectivos, lúdicos y utilitarios que motivan el acercamiento popular a los medios masivos de comunicación.

* El excesivo énfasis en la denuncia y la desatención de la construcción positiva de un futuro inmediato.

* Su ocasional olvido de la importancia del reforzamiento de la democracia y de las alianzas en frente común con otras instituciones de la sociedad civil.

* El presentar al sujeto popular más como víctima inerme y paralizada ante las estructuras y la realidad que como sujeto de transformación de las mismas.

* La idealización apolítica de ciertas experiencias de comunicación alternativa y popular de base que nunca llegaron a tocar las macroestructuras sociales.

* El no incorporar las consideraciones culturales a la comunicación.

* El despreocuparse de la aspiración y necesidad de masividad en la difusión, concentrándose en servir a organizaciones de base y sus receptores cautivos y desatendiendo al público en su conjunto.

* El olvido de la importancia de la calidad y el profesionalismo en la elaboración de los mensajes.

* Excesiva identificación con la tradición racionalista que valora únicamente los géneros analítico-conscientizadores como la información, las revistas educativas radiofónicas, los video documentales.

* La subestimación de la importancia, poder y atractivo cultural de los géneros dramáticos, narrativos, ficcionales, musicales.

* La falta de atención al autofinanciamiento, la generación autónoma de ingresos, la diversificación de fuentes financieras propias, de su público y de la cooperación internacional; específicamente la falta de inserción en el mercado de servicios incluyendo la publicidad.

Hablamos con orgullo de la comunicación alternativa y popular. Pero, ¿qué es ella? ¿Qué problemas soluciona? ¿Por qué es tan poco influyente? ¿Qué es lo alternativo en la actual coyuntura? ¿Cuánto ha ayudado en realidad al pueblo que está hoy peor que antes? ¿Con qué debe ser complementada? ¿Qué valor tiene por ejemplo para los universitarios, profesionales y gente más acostumbrada a hablar en público? ¿Para qué niveles sociales es más propia la comunicación alternativa, popular y gru\% pal? ¿Cuál es la función de los profesionales y técnicos en su desarrollo? ¿Cómo incorporar las innovaciones tecnológicas para mejorar su calidad y profesionalismo? ¿Cómo evitar la automarginación?

Martínez Terrero señala múltiples síntomas que apoyan una visión optimista de la evolución de las CAP en la región. Pero insiste en la necesidad de analizar y sistematizar las experiencias y encontrar respuestas a las preguntas planteadas para que el movimiento de comunicaciones alternativas y populares supere su actual crisis. 


\section{Contra la ceguera digital}

M ientras en Chasqui editábamos este módulo sobre Comunicación Alternativa y Popular, nos llegó por correo electrónico un mensaje del Presidente Bill Clinton y del vicePresidente Al Gore informándonos que la Casa Blanca ha instalado un sistema de recepción y procesamiento de correo electrónico ciudadano para facilitar las comunicaciones entre el gobierno de Estados Unidos y el mundo.

Este inesperado mensaje parece tener algún significado en clave. Mientras debatimos la relevancia y el futuro de la comunicación alternativa, en un mundo que parece no ser el que habitamos se trabaja en etapas avanzadas de la construcción de la autopista teleinformática que vinculará la televisión digital de alta definición con el acceso integrado a bancos de datos multimedia en una escala planetaria. Se intenta abrir el acceso a la totalidad acumulada de la producción simbólica de la humanidad, desde una terminal doméstica de TV ordenador, con la simplicidad y fidelidad de un paseo por las calles del barrio.

Las primeras versiones del hardware $y$ software ingresan ya en mercados selectos. Sus planificadores proyectan la difusión masiva en el marco de una década. Suele destacarse el abismo que separa nuestro megáfono comunitario de esa virtual autopista telemática. El curioso, lejano y hasta ingenuo, mensaje de Clinton y Gore en la casilla de

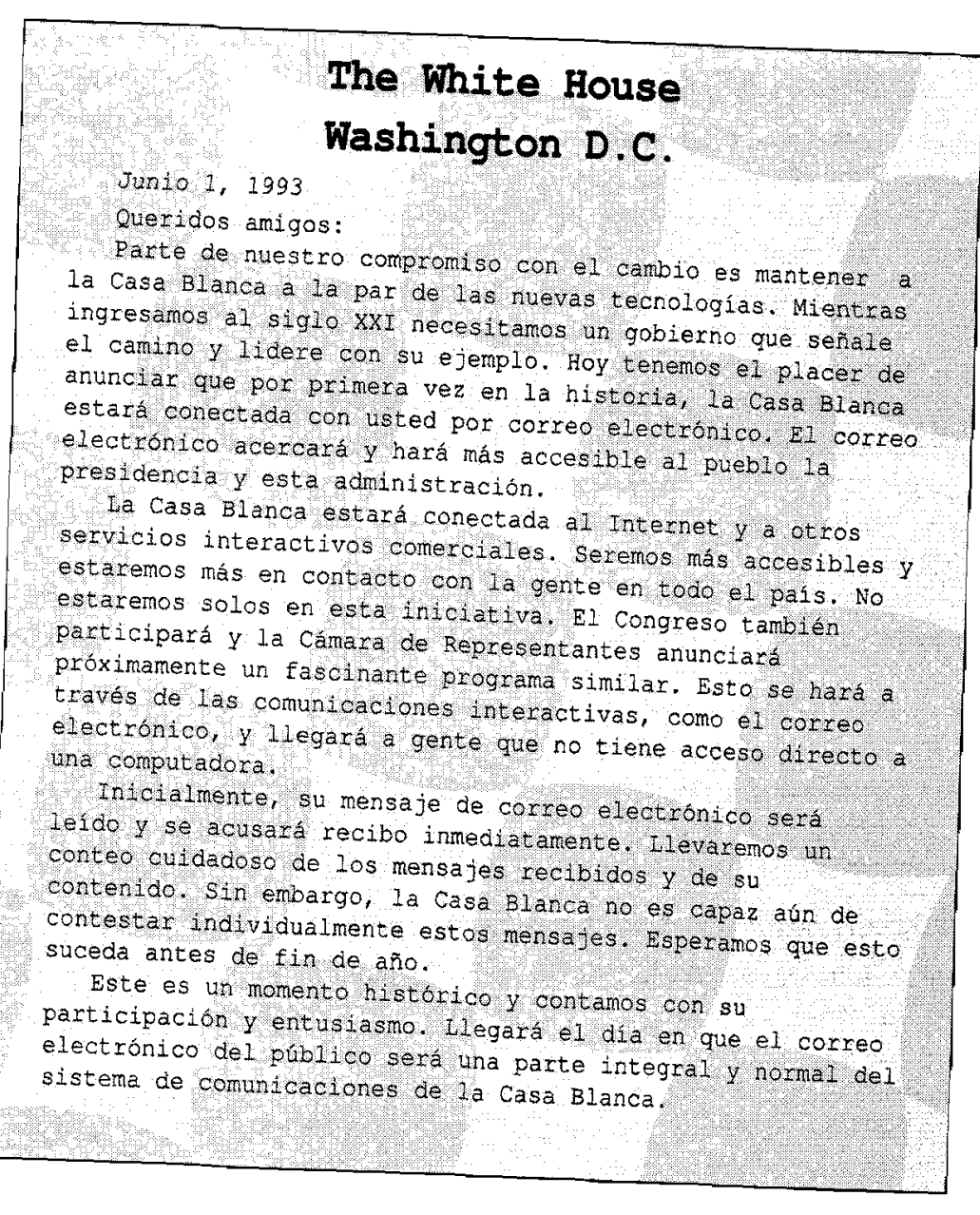

Chasqui nos sugiere que lo asombroso quizá no sea el abismo que nos separa de aquello, sino la simultaneidad y cercanía de la erupción tecnológica que nos atropella a todos.

En el encuentro no cesamos de advertir sobre la magnitud del impacto.
Los que cronograman su realización también advierten sobre el alcance de las transformaciones en curso. Pero ni ellos ni nosotros entendemos realmente cómo será ese futuro. Lo único evidente es que no estamos preparados para el contacto inminente.

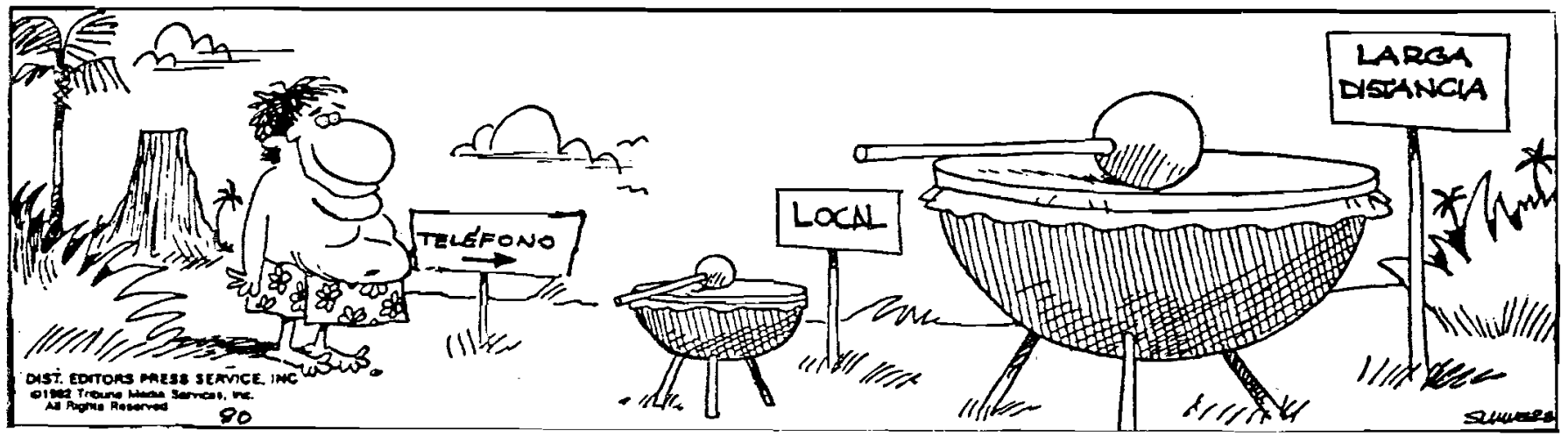

